\title{
Magnitude of intestinal parasitic infections and associated factors among food handlers working at Woldia University student's cafeteria, Northeastern Ethiopia: an institution based cross-sectional study
}

\author{
Birhan Alemnew ${ }^{1}$, Yalemzewud Belay ${ }^{2}$ and Asmamaw Demis ${ }^{3 *}$ (B)
}

\begin{abstract}
Objectives: The main aim of this study was to assess the Magnitude of intestinal parasitic infections and associated factors among food handlers working at Woldia University Student's cafeteria, Northeastern Ethiopia. Institutional based cross-sectional study was conducted among 256 study participants in Woldia university student's cafeteria, Northern Ethiopia. Systematic random sampling method was used to select the study participants. Data was collected using a standardized questionnaire by direct interviewing of study participants. Logistic regression was carried out to identify factors associated with intestinal parasitic infections.

Results: A total of 256 food handlers were enrolled making the overall magnitude of the intestinal parasite which was stool specimens positive for different diagnostic stages of parasites was found to be 43 (16.8\%). Entamoeba histolytica/dispar was the most prevalent parasites 14 (5.5\%), followed by Giardia lamblia 10 (3.9\%). Lack of food safety training $(A O R=6.58 ; 95 \% \mathrm{Cl} 2.46-17.62)$, no regular medical checkup ( $\mathrm{AOR}=2.41 ; 95 \% \mathrm{Cl} 1.47-4.24)$, no handwashing practice after toilet by soap ( $A O R=3.24 ; 95 \% \mathrm{Cl} 1.28-8.19$ ), no handwashing practice before eating by soap $(A O R=4.03 ; 95 \% \mathrm{Cl} 1.64-9.91)$ and haven't food preparation license ( $A O R=6.13 ; 95 \% \mathrm{Cl}$ 2.18-17.22) were significantly associated with parasitic infection among food handlers.
\end{abstract}

Keywords: Intestinal parasites, Food handlers, Student cafeteria, Woldia University

\section{Introduction}

Intestinal parasitic infections are a major public health problem worldwide and assessed to infect about onethird of the total population; particularly in low and middle-income countries (LMIC) and constituting the greatest cause of illness and disease in children's and food handlers with up to 2 million deaths are estimated per year [1-3]. According to WHO estimates, more than half a million deaths per year in Africa are due to food

\footnotetext{
*Correspondence: asmamawdemis@gmail.com

${ }^{3}$ Department of Nursing, College of Health Sciences, Woldia University, P.O.Box:400 Woldia, Ethiopia

Full list of author information is available at the end of the article
}

and water-borne related diseases which shows the tip of the iceberg, as many more cases that are sporadic went unreported [4]. In Ethiopia, intestinal parasitic infections are the major causes of mortality and morbidity causing a series of public health problems such as malnutrition, anaemia, and growth retardation as well as a higher susceptibility to other infections $[1,2]$. Poor environmental sanitation, irrigation, overcrowding, resettlement, and low altitude were suggested to be responsible for the high prevalence of intestinal parasitic infection in the country [3-5]. Proper educations, protocols, training programs on the hygienic practices and regular medical checkup among food-handlers help to control the prevalence of intestinal pathogens and parasites at certain limits $[2,6]$. 
Different studies conducted in Ethiopia showed that there was a high magnitude of enteric pathogens among food handlers working at university student's cafeteria, due to improper hygienic practices, improper fingernail trimming and unavailability of standard protocols $[2,7,8]$. The most prevalent intestinal protozoan parasites in Ethiopia are Giardia lamblia and Entamoeba histolytica/dispar. Helminthic infection includes Ascaris lumbricoides, Trichuris trichuriasis and Taenia species [8, 9]. In spite of the public health importance of these intestinal parasites and the potential consequences, there was no enough data about the magnitude of intestinal parasites among food handlers in Woldia University. Therefore, this study was aimed to assess the magnitude and factors associated with intestinal parasitic infections among food handlers working at Woldia University Student's cafeteria, Northeastern Ethiopia.

\section{Main text \\ Methods \\ Study setting, design and period}

Institutional based cross-sectional study design was conducted from March to June 2018 at Woldia University student cafeteria. Woldia University is one of the higher governmental university in Ethiopia which was found in Amhara region and located $521 \mathrm{~km}$ far from Addis Ababa, the capital city of Ethiopia. It has two campuses namely, Woldia (main campus) and Merssa College of Agriculture campus but our study was conducted in the main campus at Woldia.

\section{Sample size determination and sampling technique}

The sample size was determined by a computer based on Epi info 7 software Stat Cal using single population proportion formula. The actual sample size is calculated using a single population proportion formula.

$$
\mathrm{n}=\frac{\left(\mathrm{Z}_{\alpha / 2}\right)^{2} \mathrm{p}(1-\mathrm{P})}{\mathrm{d}^{2}}=\frac{(1.96)^{2} * 0.523(1-0.523)}{(0.05)^{2}}=383,
$$

where $\mathrm{n}$ is the minimum sample size required for the study; $\mathrm{Z}$ is the standard normal distribution $(\mathrm{Z}=1.96)$ with a confidence interval of $95 \%$; $P$ is the prevalence of intestinal parasitic infections in Mekelle University, Ethiopia $(\mathrm{p}=52.3 \%)$ [10]. $\mathrm{d}$ is a tolerable margin of error $(\mathrm{d}=0.05)$

Since the total number of source population was 595 and below 10,000 a correction formula was used to adjust the sample size as follows:

$$
\mathrm{nf}=\frac{\mathrm{n}}{1+\mathrm{n} / \mathrm{N}}=\frac{383}{1+383 / 595}=233 .
$$

By considering a $10 \%$ non-response rate, the final sample size of the study was 256 .

\section{Method of data collection}

Socio-demographic data and associated risk factors including institution and home-related data were collected using pre-tested structured questionnaire in a face to face interview. Stool specimens were collected from food handlers in a clean stool cup pre-labelled with study subject identification code at Woldia health center. A portion of the specimen (approximately 1-2 mg) was processed using direct saline preparation examined under $10 \times$ and $40 \times$ objective lenses of a light microscope for detection of helminths ova and larvae, protozoa cysts and trophozoites. After completion of direct stool examination, $1 \mathrm{~g}$ of each sample was emulsified in $10 \%$ formalin solution and examined in formol-ether concentration technique.

\section{Data quality assurance}

The training was given for data collectors and supervisors about techniques of data collection and briefed on each question included in the data collection tool. The pre-test was conducted to ensure the validity of the tool, and then the correction was made before the actual data collection. Principal investigator and supervisors were checked on the spot and reviewed all the questionnaires to ensure completeness and consistency of the information collected and immediate action was taken accordingly. Double data entry was done by two data clerks and consistency of the entered data was cross-checked by comparing the two separately entered data.

\section{Data processing and analysis}

The collected data were coded, cleaned, and entered into Epi data version 4.2 and exported to SPSS window version 24 for analysis. The binary logistic regression model was used to assess the association between independent variables and intestinal parasitic infections. All variables with $\mathrm{P}$-value $\leq 0.25$ in the bivariable analysis were included in the final model of multivariate analysis to control all possible confounders. Multi-collinearity was checked to see the linear correlation among the independent variables by using standard error. Variables with a standard error of $>2$ were dropped from the multivariable analysis. Model fitness was checked with the Hosmer-Lemeshow test. Adjusted odds ratio with 95\% CI was estimated to identify the factors associated with Intestinal parasitic infections using multivariable logistic regression analysis level of statistical significance was declared at $\mathrm{p}$-value $<0.05$. 


\section{Results}

Socio-demographic characteristics and hygienic practice of food handlers

A total of 256 study participants were involved in the study with a response rate of $100 \%$. Among them 164 (64.1\%) food handlers were female. The mean age of the study participants was 25.24 ( $\pm 3.26 \mathrm{SD})$ years. About 116 (45.5\%) were in age groups of 20-24 years. The majority of food handlers 210 (82\%) had attended primary and above education. Of the total study participants, 205 (80.1\%) had completely trimmed their nails, 230 (89.8\%) were used hair cover during work, $209(81.6 \%)$ of food handlers were used gown (Additional file 1: Table S1).

\section{Working House condition and practice-related factors of food handlers}

Concerning working house condition, 105 (41\%) and 106 (41.4\%) had one room and window respectively. One hundred thirty-nine (54.3\%) had fair ventilation system whereas 183 (71.5\%) had good illumination systems. Regarding latrine condition, 149 (58.2\%) had latrine with segregated water and 196 (76.6\%) has clean by cleanliness (Table 1).

\section{The magnitude of intestinal parasite}

Both direct microscopic and concentration techniques were used for identifying intestinal parasites from 256 stool specimens of food handlers. The overall prevalence of intestinal parasite positive for different intestinal

Table 1 Working house condition and practice of food handlers working at Woldia University Student's cafeteria, Northeastern Ethiopia, 2018 ( $\mathrm{N}=\mathbf{2 5 6})$

\begin{tabular}{|c|c|c|c|}
\hline Variables & Characteristics & Frequency $(n=256)$ & Percentage \\
\hline \multirow[t]{3}{*}{ Houseroom of food handlers } & One room & 105 & 41.0 \\
\hline & Two rooms & 69 & 27.0 \\
\hline & Three rooms & 82 & 32.0 \\
\hline \multirow[t]{3}{*}{ Number of windows for food handlers } & One window & 106 & 41.4 \\
\hline & Two windows & 78 & 30.5 \\
\hline & Three windows & 72 & 28.1 \\
\hline \multirow[t]{3}{*}{ Ventilation system of the house for food handlers } & Good & 90 & 35.2 \\
\hline & Fair & 139 & 54.3 \\
\hline & Bad & 27 & 10.5 \\
\hline \multirow[t]{2}{*}{ Illumination system of the house for food handlers } & Good & 183 & 71.5 \\
\hline & Bad & 73 & 28.5 \\
\hline \multirow[t]{2}{*}{ Type of floor of the house for food handlers } & Cement & 137 & 53.5 \\
\hline & Soil & 119 & 46.5 \\
\hline \multirow[t]{2}{*}{ Type of kitchen the house of food handlers } & Attached to the main house & 87 & 34.0 \\
\hline & Detached to the main house & 169 & 66.0 \\
\hline \multirow[t]{2}{*}{ Cleanliness of the house of food handlers } & Very good & 97 & 37.9 \\
\hline & Good & 159 & 62.1 \\
\hline \multirow[t]{2}{*}{ Use of water of food handlers } & Private pipe & 110 & 43.0 \\
\hline & Common pipe & 146 & 57.0 \\
\hline \multirow[t]{2}{*}{ Type of latrine for food handlers } & Has water segregation & 149 & 58.2 \\
\hline & No water segregation & 107 & 41.8 \\
\hline \multirow[t]{2}{*}{ Cleanliness of latrine for food handlers } & Clean & 196 & 76.6 \\
\hline & Not clean & 60 & 23.4 \\
\hline \multirow[t]{2}{*}{ Liquid disposal methods for food handlers } & Open field & 90 & 35.2 \\
\hline & Use segregation & 166 & 64.8 \\
\hline \multirow[t]{3}{*}{ Solid waste disposal system of food handlers } & Hole & 170 & 66.4 \\
\hline & Open field & 49 & 19.1 \\
\hline & Municipal body & 37 & 14.5 \\
\hline \multirow[t]{2}{*}{ Use of hair cover during food preparations } & Yes & 230 & 89.8 \\
\hline & No & 26 & 10.2 \\
\hline
\end{tabular}


parasite species was found to be $16.8 \%$ (95\% CI $12.1 \%-$ 21.5\%). Entamoeba histolytica/dispar was the most prevalent parasites 14 (5.5\%), followed by Giardia lamblia 10 (3.9\%), Ascaris lumbricoides 9 (3.5\%), Strongloid stercolaris 3 (1.2\%), Trichuris trichiura 3 (1.2\%), Taenia species 2 (0.8\%), and Hookworm 2 (0.8\%).

\section{Factors associated with intestinal parasitic infection}

The odds of food handlers who didn't always wash their hand after toilet by soap were three times more likely acquired intestinal parasitic infection than those who wash their hands after toilet by soap (AOR $=3.24 ; 95 \%$ CI 1.28-8.19). Concerning food handlers regular medical checkup and had food preparation license, food handlers who had regular medical checkup were 2.4 times $(\mathrm{AOR}=2.41 ; 95 \% \mathrm{CI} 1.47-4.24)$ and food handlers who had food preparation license were 6.13 times $(\mathrm{AOR}=6.13$; 95\% CI 2.18-17.22) more likely acquired intestinal parasitic infection as compared with their counterparts. We also found that the odds of having food safety hygiene and training practices were 6.58 times higher $(\mathrm{AOR}=6.58 ; 95 \% \mathrm{CI} 2.46-17.62)$ among food handlers than food handlers that had no training opportunity. Those food handlers who did not trim their fingernail were 3.11 times more likely $(\mathrm{AOR}=3.11$; 95\% CI 1.14-8.67) infested than those who did regularly (Table 2).

\section{Discussion}

The overall prevalence of intestinal parasitic infection among food handlers working in Woldia university student cafeteria was $16.8 \%$. This finding was similar with studies from different parts of Ethiopia such as $14.5 \%$ Aksum Town [13], 15\% Wollo University student's cafeteria [14]. However, the prevalence of IPIs was low as compared to studies conducted in Ethiopia, 41.1\% in Bahir Dar, Amhara [15], 52.4\% Mekelle University student cafeteria, Tigray [10], 45.3\% Addis Ababa University student's cafeteria, Addis Ababa [11], 33\%, in Jimma University Specialized Hospital, Southwest Ethiopia [16], 36\% Arba Minch University, Southern Ethiopia [19], 25.2\% Haramaya University cafeterias, Eastern Ethiopia [12], 61.9\% among food handlers at Prison, East and West Gojjam [5] and $43.38 \%$ Saudi Arabia [18]. The possible reason might be due to good personal hygiene practices and environmental sanitation, continuous health-promotion practices, time of the study and geographical variation of the participants.

In our study, Entamoeba histolytica/dispar was the most prevalent parasites 14 (5.5\%), followed by Giardia lamblia 10 (3.9\%) among food handlers working in Woldia university student cafeteria. In contrast, the most abundant parasite of Arba Minch University students' cafeteria, were Entamoeba histolytica/dispar 48 (14\%) followed by Ascaris lumbricoides 32 (9.27\%) [17], Haramaya University cafeterias were Entamoeba histolytica/dispar (46.7\%) and Ascaris lumbricoides (14.3\%) [12], Wollo University student's cafeteria were Enttamoeba. histolytica (5.5\%) followed by Ascaris lumbricoides (4\%) and then Gardia lamblia (3\%) [14]. However, the predominant organism were found to be Ascaris lumbricoides in other studies which was conducted in Jimma University Specialized Hospital [16] and Gondar Ethiopia [9]. This might be due to food habits, cultural factors and geographical conditions.

These findings indicated that lack of food safety training, no regular medical checkup, no handwashing practice after toilet and after eating by soap were significantly associated with parasitic infection among food handlers. The odds of food handlers who didn't always wash their hand after toilet by soap were three times more likely acquired intestinal parasitic infection than those who wash their hands after toilet, which is supported with the study conducted in Arba Minch University, Ethiopia [19], Haramaya University [12] and at Prison, East and West Gojjam [5]. This might be due to the fact that those food handlers who didn't wash their hands with soap after toilet may infest with intestinal infection during eating, drinking and cooking.

The odds of food handlers who hadn't received regular a medical checkup were 2.4 times more likely infested with intestinal parasites as compared with those food handlers who had received medical checkup. This is in line with the study conducted in Aksum Town [13] and Wollo University student's cafeteria [14]. This might be due to the fact that those food handlers who hadn't received medical checkup may not know their status, as a result, they became a carrier and infested with intestinal parasites.

Food handlers who hadn't taken food safety training were 6.58 times more infested with intestinal parasites as compared with food handlers who took food safety training. This is in line with the study conducted in Aksum Town [13] and Dessie town [6]. This might be due to the fact that those food handlers who didn't take food safety training may not understand the way of prevention and control mechanism, as a result, they became highly infested with intestinal parasites.

Food handlers who did not trim their fingernail were 3 times more likely infested with intestinal parasites than those who trimmed their fingers regularly. This is similar to the study conducted in Wollo University student's cafeteria [14], Arba Minch University, Ethiopia [19] and at Prison of East and West Gojjam [5]. This 
Table 2 Bivariable and multivariable logistic regression analysis of factors associated with intestinal parasitic infections among food handlers working at Woldia University Student's Cafeteria, Northeastern Ethiopia, 2019 ( $n=256)$

\begin{tabular}{|c|c|c|c|c|}
\hline \multirow[t]{2}{*}{ Variables } & \multicolumn{2}{|c|}{ Intestinal parasitic infections } & \multirow[t]{2}{*}{ COR $(95 \% \mathrm{Cl})$} & \multirow[t]{2}{*}{ AOR $(95 \% \mathrm{Cl})$} \\
\hline & Positive (\%) & Negative (\%) & & \\
\hline \multicolumn{5}{|l|}{ Sex } \\
\hline Male & $15(16.3)$ & $77(83.7)$ & 1 & 1 \\
\hline Female & $28(17.1)$ & $136(82.9)$ & $0.95(0.48-1.88)$ & $1.79(0.62-5.18)$ \\
\hline \multicolumn{5}{|l|}{ Age } \\
\hline $15-19$ & $4(30.8)$ & $9(69.2)$ & $0.41(0.11-1.47)$ & $1.91(0.40-9.09)$ \\
\hline $20-24$ & $18(15.5)$ & $98(84.5)$ & 1.00 & 1.00 \\
\hline $25-29$ & $12(16.9)$ & $59(83.1)$ & $0.89(0.40-1.99)$ & $0.53(0.06-5.10)$ \\
\hline $30-34$ & $5(17.2)$ & $24-(82.8)$ & $0.84(0.28-3.49)$ & $1.31(0.27-6.41)$ \\
\hline$\geq 35$ & $4(14.8)$ & $23(85.2)$ & $1.04(0.32-3.38)$ & $1.71(0.24-12.22)$ \\
\hline \multicolumn{5}{|c|}{ Hand washing after toilet with a soap } \\
\hline Yes & $14(7.6)$ & $169(82.4)$ & 1 & 1 \\
\hline No & $29(39.7)$ & $44(60.3)$ & $7.96(3.87-16.32)$ & $3.24(1.28-8.19)^{*}$ \\
\hline \multicolumn{5}{|c|}{ Hand washing before eating food with a soap } \\
\hline Yes & $17(8.6)$ & $182(81.4)$ & 1 & 1 \\
\hline No & $26(45.6)$ & $31(54.4)$ & $8.98(4.37-18.45)$ & $4.03(1.64-9.91)^{* *}$ \\
\hline \multicolumn{5}{|c|}{ Fingernail trimming } \\
\hline Yes & $22(10.7)$ & $183(89.3)$ & 1 & 1 \\
\hline No & $21(41.2)$ & $30(58.8)$ & $3.76(1.88-7.51)$ & $3.11(1.14-8.67)^{* * *}$ \\
\hline \multicolumn{5}{|c|}{ Use of apron when handling food } \\
\hline Yes & $37(17.7)$ & $172(82.3)$ & 1 & 1 \\
\hline No & $6(12.8)$ & $41(87.2)$ & $0.68(0.27-1.72)$ & $0.37(0.09-1.50)$ \\
\hline \multicolumn{5}{|c|}{ Use of hair cover during work of food handlers } \\
\hline Yes & $38(16.5)$ & $192(83.5)$ & 1 & 1 \\
\hline No & $5(19.2)$ & $21(80.8)$ & $1.20(0.43-3.34)$ & $0.70(0.17-2.81)$ \\
\hline \multicolumn{5}{|c|}{ Year of service } \\
\hline$<1$ year & $9(18.7)$ & $39(81.3)$ & $0.90(0.40-2.03)$ & $0.29(0.05-1.71)$ \\
\hline $1-5$ years & $32(17.6)$ & $150(82.4)$ & 1 & 1 \\
\hline $6-10$ years & $2(8.3)$ & $24(81.7)$ & $2.54(0.57-11.31)$ & $0.54(0.08-3.84)$ \\
\hline \multicolumn{5}{|c|}{ Food safety training } \\
\hline Yes & $22(10.6)$ & $186(89.4)$ & 1 & 1 \\
\hline No & $21(43.7)$ & $27(52.3)$ & $6.57(3.20-13.52)$ & $6.58(2.46-17.62)^{* * * *}$ \\
\hline \multicolumn{5}{|c|}{ Medical checkup for IPs } \\
\hline Yes & $25(11.8)$ & $186(88.2)$ & 1 & 1 \\
\hline No & $18(40.0)$ & $27(60.0)$ & $3.06(1.45-6.47)$ & $2.41(1.47-4.24) * * *$ \\
\hline \multicolumn{5}{|c|}{ Having a license for food handling practice } \\
\hline Yes & $23(11.1)$ & $184(88.9)$ & 1 & 1 \\
\hline No & $20(40.8)$ & $29(59.2)$ & $5.52(2.70-11.20)$ & $6.13(2.18-17.22)^{* * * *}$ \\
\hline \multicolumn{5}{|c|}{ Took medication } \\
\hline Yes & $16(27.6)$ & $42(72.4)$ & 1 & 1 \\
\hline No & 27 (13.6) & $171(86.4)$ & $2.41(1.19-4.89)$ & $0.51(0.18-1.39)$ \\
\hline
\end{tabular}

Significant at: ${ }^{*} \mathrm{P}=0.013,{ }^{* * \mathrm{P}}=002,{ }^{* * * \mathrm{P}}=0.03,{ }^{* * * * \mathrm{P}}=0.001,1=$ reference

might be due to the fact that those food handlers didn't trim their fingernail which makes them carrier of parasites in the fingernail, as a result, they became more infested with intestinal parasites.

\section{Conclusions}

Generally, the overall magnitude of intestinal parasitic infection among food handlers at Woldia university student cafeteria was found relatively low as compared from 
another public university within the country. However, food safety training, fingernail trimming practice, handwashing with soap after toilet, hand washing after eating and medical checkups were the potential factors for intestinal parasitic infection. Therefore, regular and contentious training on food safety and handwashing practice and regular periodic medical checkup are essential strategies for prevention of intestinal parasitic infections. Besides, further studies should be undertaken on bacterial isolates and associated risk factors among those food handlers at the study area.

\section{Limitations of the study}

The cross-sectional nature of the study design limits the applicability of the findings in establishing causality between the variables.

\section{Supplementary information}

Supplementary information accompanies this paper at https://doi. org/10.1186/s13104-019-4777-z.

Additional file 1: Table S1. Distribution of socio-demographic characteristics and hygienic practice of food handlers working at Woldia University Student's cafeteria, Northeastern Ethiopia, $2018(\mathrm{~N}=256)$.

\section{Abbrevations}

AOR: Adjusted Odds Ratio; CDC: Center for Disease Control and Prevention; Cl: Confidence Interval; IPIs: Intestinal Parasitic Infections; IRB: Institutional Review Board; SPSS: Statistical Package for Social Sciences; WDU: Woldia University; WHO: World Health Organizations.

\section{Acknowledgements}

The authors would like to thank our data collectors and supervisors for their invaluable effort to make this study real. The author's deep gratitude also goes to our study subjects who were volunteered and took their time to give us all the relevant information for the study.

\section{Author's contributions}

$\mathrm{BA}, \mathrm{YB}$, and $\mathrm{AD}$ was the investigator who initiated the research, wrote the research proposal, conducted the fieldwork, supervised data entry, analyzed the data and wrote the manuscript. All authors read and approved the final manuscript.

\section{Funding}

The research was self-funded. The authors' independently design the study, analyze and interpret the data, prepared the manuscript.

\section{Availability of data and materials}

All related data has been presented within the manuscript. The dataset supporting the conclusions of this article is fully available from the authors on request.

\section{Ethics approval and consent to participate}

Ethical approval was obtained from Woldia University Institutional Review Board (WDU/IRB). All the study participants were informed about the purpose of the study, their right to refuse. The participants enrolled in the study were informed about the study objectives, expected outcomes, benefits and the risks associated with it. The tool had attached consent form. Written consent was taken from the participants before the interview. In this study there were no respondents less than 16 years old as a result, permission was obtained directly from food handlers. Confidentiality was ensured by anonymizing the respondents' name. Food handlers who have found to be positive for intestinal parasite were treated.

\section{Consent for publication}

Not applicable.

\section{Competing interests}

The authors declare that they have no competing interests.

\section{Author details}

${ }^{1}$ Department of Medical Laboratory Sciences, College of Health Sciences, Woldia University, Woldia, Ethiopia. ${ }^{2}$ Department of Public Health, College of Health Sciences, Woldia University, Woldia, Ethiopia. ${ }^{3}$ Department of Nursing, College of Health Sciences, Woldia University, P.O.Box:400 Woldia, Ethiopia.

Received: 30 July 2019 Accepted: 1 November 2019

Published online: 08 November 2019

\section{References}

1. Mehraj V, Hatcher J, Akhtar S, Rafique G, Beg MA. Prevalence and factors associated with intestinal parasitic infection among children in an urban slum of Karachi. PLoS ONE. 2008:3(11):e3680.

2. World Health Organization. Food safety and foodborne illness. Geneva: WHO; 2007.

3. World Health Organization. Consultation to develop a strategy to estimate the global burden of foodborne diseases. Geneva: WHO Consultation; 2006.

4. National Food Safety Systems in Africa. A situation analysis. In: FAO/WHO Regional Conference on Food Safety for Africa; Harare, Zimbabwe; 2005

5. Asires A, Wubie M, Reta A. Prevalence and Associated Factors of Intestinal Parasitic Infections among Food Handlers at Prison, East and West Gojjam, Ethiopia. Adv Med. 2019. https://doi.org/10.1155/2019/2101089.

6. Adane M, Teka B, Gismu Y, Halefom G, Ademe M. Food hygiene and safety measures among food handlers in street food shops and food establishments of Dessie town, Ethiopia: a community-based cross-sectional study. PLoS ONE. 2018;13(5):e0196919.

7. Mengist A, Mengistu G, Reta A. Prevalence and antimicrobial susceptibility pattern of Salmonella and Shigella among food handlers in catering establishments at Debre Markos University, Northwest Ethiopia. Int J Infect Dis. 2018;75:74-9.

8. Mulu W, Abera B, Yimer M, Hailu T, Ayele H, Abate D. Bacterial agents and antibiotic resistance profiles of infections from different sites that occurred among patients at Debre Markos Referral Hospital, Ethiopia: a cross-sectional study. BMC Res Notes. 2017;10(1):254.

9. Andargie G, Kassu A, Moges F, Huruy K. Prevalence of bacteria and intestinal parasites among food-handlers in Gondar Town, Northwest Ethiopia. J Health Popul Nutr. 2008;26:451.

10. Gebreyesus A, Adane K, Negash L, Asmelash T, Belay S, Alemu M, Saravanan M. Prevalence of Salmonella typhi and intestinal parasites among food handlers in Mekelle University student cafeteria, Mekelle, Ethiopia. Food Control. 2014:44:45-8.

11. Aklilu A, Kahase D, Dessalegn M, Tarekegn N, Gebremichael S, Zenebe S, Desta K, Mulugeta G, Mamuye Y, Mama M. Prevalence of intestinal parasites, salmonella and shigella among apparently health food handlers of Addis Ababa University student's cafeteria, Addis Ababa, Ethiopia. 2014

12. Marami D, Hailu K, Tolera M. Prevalence and associated factors of intestinal parasitic infections among asymptomatic food handlers working at Haramaya University cafeterias, Eastern Ethiopia. Ann Occup Environ Med. 2018;30:53.

13. Gezehegn D, Abay M, Tetemke D, Zelalem H, Teklay H, Baraki Z, et al. Prevalence and factors associated with intestinal parasites among food handlers of food and drinking establishments in Aksum Town, Northern Ethiopia. BMC Public Health. 2017;17(1):819.

14. Kebede E, Seid A, Akele S. Prevalence and associated risk factors of intestinal parasitic infections among asymptomatic food handlers in Wollo University student's cafeteria, Northeastern Ethiopia. BMC Res Notes. 2019;12(1):139.

15. Abera B, Biadegelgen F, Bezabih B. Prevalence of Salmonella typhi and intestinal parasites among food handlers in Bahir Dar Town, Northwest 
Ethiopia. Ethiop J Health Develop. 2010. https://doi.org/10.4314/ejhd. v24i1.62944.

16. Girma H, Getner B, Zeleke M. Prevalence of intestinal parasites among food handlers at the cafeteria of Jimma University Specialized Hospital, Southwest Ethiopia. Asian Pac J Trop Dis. 2017;7:1-5.

17. Mama M, Alemu G. Prevalence and factors associated with intestinal parasitic infections among food handlers of Southern Ethiopia: crosssectional study. BMC Public Health. 2016;16:105.

18. Omar H, Ibraheem M, Najoua A. Prevalence of intestinal parasite infections among patients in local public hospitals of Hail, North western Saudi Arabia. Asian Pac J Trop Med. 2016;9(1):44-8.
19. Mohammed M, Getaneh A. Prevalence, antimicrobial susceptibility patterns and associated risk factors of Shigella and Salmonella among food handlers in Arba Minch University South Ethiopia. BMC Infect Dis. 2016;16:686.

\section{Publisher's Note}

Springer Nature remains neutral with regard to jurisdictional claims in published maps and institutional affiliations.
Ready to submit your research? Choose BMC and benefit from:

- fast, convenient online submission

- thorough peer review by experienced researchers in your field

- rapid publication on acceptance

- support for research data, including large and complex data types

- gold Open Access which fosters wider collaboration and increased citations

- maximum visibility for your research: over 100M website views per year

At BMC, research is always in progress.

Learn more biomedcentral.com/submissions 